Les Classique de la decouverte scientifique

(r) Traité élémentaire de chimie de Lavoisier Pp. xxxviii $+191+2$ plates.

(2) Leçons de philosophie chimique

Par J.-B. Dumas. Pp. xxviii $+270+2$ plates.

(3) La synthèse totale en chimie organique Mémoires de MM. Wöhler, Gerhardt, M. Berthelot, Le Bel, Van't Hoff, Jungfleisch, Ladenburg, Pasteur. Préface et commentaires par Marcel Delépine. Pp. viii $+144+8$ plates.

(Paris : Gauthier-Villars, 1937.) 21 francs each.

$\mathrm{N}$ reprinting these three classics of French chemistry 1 with introductions, an important service has been rendered to the study of the history of chemistry.

(1) The famous "Traité" of Lavoisier, with an introduction by Le Chatelier, is reprinted in part only, but the important sections have been retained. The first part, giving the theoretical views of Lavoisier, has been reprinted in full; the second part of the original work, containing tables of compounds, has been omitted entirely, which has resulted in a few important sections being wanting, and a third part, dealing with apparatus, has been abridged. The illustrations have been incorporated in the text. The present work will serve the needs of students but it cannot be regarded as a critical edition. No indication is given as to which edition of the original has been followed for the text, and the title-page as reproduced does not correspond with either of the editions of 1789 .

(2) The work by Dumas has been reprinted in full, with an introduction by G. Urbain; it is essentially historical and is still of considerable value. The style is lively and the choice of subjects is an excellent one. This volume will not only be read with profit by students but also will be useful to specialists.

(3) The volume on organic synthesis, with an introduction by $\mathbf{M}$. Delépine, contains a very appropriate choice of texts in French, beginning with extracts from the registers of the Academy dealing with experiments of Bourdelin, extracts from the paper by Rouelle on urine (in which urea is first described) and from the paper describing the work of Fourcroy and Vauquelin in which this substance is first isolated, a translation of Wöhler's paper on the synthesis of urea, extracts from Gerhardt's "Traité", long extracts from Berthelot's "Chimie organique fondée sur la synthèse" and other publications by Berthelot, papers of van't Hoff, Le Bel, Jungfleisch and Ladenburg, and notes on the work of Pasteur and recent publications.

The three volumes contain portraits.

\section{Science (K'o Hsüeh)}

Vol. 22. Nos. 1 and 2 (January-February, 1938). (Shanghai : Science Society of China, 1938.) 50 cents (6d.).

A $\mathrm{T}$ this time of unparalleled unhappiness for I China, it is particularly interesting to see that scientific work is going on and that sufficient support is available for the circulation of a monthly journal very similar in its aims and format to NATURE.

The January-February number, which lies before us, opens with a translation of the Mather Lecture of the late Right Hon. Ramsay MacDonald, published in NATURE of October 30 of last year. This is followed by more specialized articles, such as a mathematical paper by Mr. H. C. Wang and an account of work on pentosan fermentation by Mr. C. L. Kuo. Anthro. pology is represented by an especially interesting review of the geographical distribution of the "Jew's Harp" in the Orient, based on a good deal of British field work as well as on Mr. H. Liu's own researches and drawing upon the descriptions of the instruments in classical Chinese literature. Another interesting contribution is from Mr. C. F. Hsü, who lists a further thirty indigenous Chinese drugs, giving their names, characteristic place of origin, traditional therapeutic use and the nature of the active principles found in them by modern chemical methods. An appeal is made to botanists to help to identify these plants which have been known for so many centuries in the Chinese classics.

Besides these articles there are accounts of contemporary events such as the Galvani celebrations at Bologna, the ceremonies attending Prof. H. Wieland's sixtieth birthday, and various congresses. Translations of certain reviews from NATURE are also given.

The journal is printed in the modern 'scientific' style extremely well and gives an excellent im. pression. It should be realized that scarcely twenty years have passed since Western science began to be studied seriously in China. The application of Western science to Chinese conditions is by no means easy, since a large body of men educated in this tradition has not yet grown up. Moreover, the glaring necessities of the social situation require an emphasis on studies of immediate practical importance. Chinese scientific men are thus especially well aware of their social responsibilities. The recent discussions in NATURE of such problems, having been in the minds of Chinese scientific workers for many years past, will find a very sympathetic understanding in China.

G. D. LU.

Naturwissenschaftliche Erkenntniss und ihre Methoden Von M. Hartmann und W. Gerlach. Pp. v+70. (Berlin : Julius Springer, 1937.) 2.40 gold marks.

TWO addresses on the origin and methods of progress in biology and on theory and experiment in the exact sciences, delivered in September 1936 by Prof. Hartmann of Berlin and Prof. Gerlach of Munich before the Gesellschaft Naturforscher und Ärzte have been issued in pamphlet form, the second with considerable additions extending it to 49 pages as against 21 for the first. The aim of both addresses is to show that the methods by which science is advanced are the same in principle in all fields. In biology the methods are illustrated by the development of the chromosome theory of heredity, and in physics by the ways in which the detailed study of the physical memoirs of the last hundred years rather than philosophical discussions have made progress possible. Many examples of the way in which theory and experiment have reacted fruitfully on each other and stimulated growth are given by Prof. Gerlach, some taken from the newer, but more from classical physics. 